\title{
Caracterización de microorganismos solubilizadores de fosfato aislados de suelos destinados al cultivo de uchuva (Physalis peruviana L.)
}

\section{Characterization of phosphate solubilizing microorganisms isolated from soils planted with cape gooseberry (Physalis peruviana L.)}

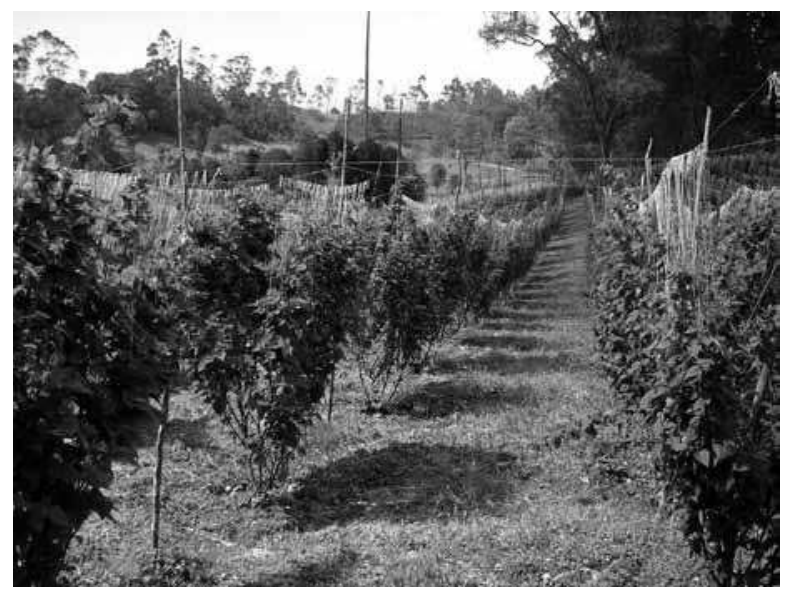

JULIANA M. BECERRA 1,2

DIANA QUINTERO ${ }^{1}$

MARÍA MARTÍNEZ ${ }^{1}$

ADRIANA MATIZ ${ }^{1}$

Cultivo de uchuva en Granada, Cundinamarca.

Foto: G. Fischer

\section{RESUMEN}

Muestras de suelo de cultivos de uchuva provenientes de dos zonas productoras de Cundinamarca (Colombia), se usaron para aislar microorganismos solubilizadores de fosfato. Se utilizó el medio SMRS1 para realizar pruebas cualitativas de solubilización por la formación de halos de aclaración con roca fosfórica. Se aislaron cinco cepas con capacidad solubilizadora y posteriormente se seleccionaron según sus índices de solubilización (IS). Tres de las cinco presentaron mejor solubilización en el medio SMRS1, obteniéndose valores de IS entre 2,4 y 3,0. Las cepas seleccionadas fueron identificadas por medio de kits API como Candida famata, Aeromonas hydrophila y Rahnella aquatillis. Posteriormente se realizaron curvas de crecimiento para cada una de estas cepas, evaluándose tres tratamientos: medio AG modificado, medio AG y medio BR utilizando como controles el medio SMRS y SMRS1. La evaluación de la actividad fosfatasa se realizó en dos fases, cada una en condiciones diferentes, por el método de p-nitrofenilfosfato. Se obtuvo producción de fosfatasas ácidas. Aunque en ambas fases la actividad fosfatasa de las cepas individuales fue detectada en muy bajas concentraciones, se encontró que su actividad se potencializaba al utilizar su inóculo mixto. Al no presentarse antagonismo entre las cepas, podrían ser una opción para el desarrollo de un futuro bioinoculante mixto apto para suelos ácidos. Además se encontró que el medio BR puede ser una alternativa viable para el crecimiento de microorganismos solubilizadores de fosfatos.

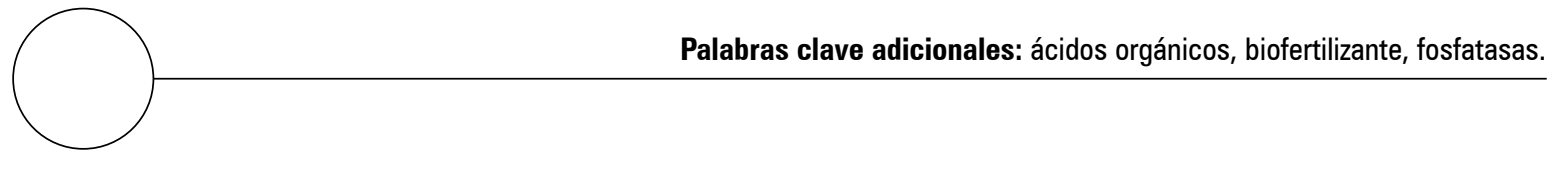

Programa de Microbiología Industrial, Pontificia Universidad Javeriana, Bogotá (Colombia).

Autor para correspondencia: julianitam3@gmail.com 


\section{ABSTRACT}

Soil samples of cape gooseberry crops from two production areas of Cundinamarca (Colombia) were used to isolate phosphate solubilizing microorganisms. The culture medium SMRS1 was used to perform qualitative solubilization tests by identifying the formation of clear zones around the colonies with rock phosphate. Five strains were isolated with a solubilizing capacity and subsequently three out of the five were selected according to their solubilization index. The P-solubilization index of these isolates ranged from 2.4 to 3.0. The selected strains were identified with API kits as Candida famata, Aeromonas hydrophila and Rahnella aquatilis. Then, a growth curve was made for each, testing three different culture mediums considered as treatments: modified AG medium, AG medium and quinoa BR medium; with SMRS and SMRS1 as the controls. The evaluation of phosphatase activity was carried out in two phases, each under different conditions, with the p-nitrophenylphosphate method. A production of acid phosphatases was observed. Although the phosphatase activity of individual strains was detected at very low concentrations in both phases, we found that their activity can be potentiated as a mixed inoculum. As no antagonism was present between strains, they could be a suitable option for the future development of mixed bioinoculants for acid soils. The BR medium was also found to potentially be a viable alternative for the growth of phosphate solubilizing microorganisms.

Additional key words: organic acids, biofertilizer, phosphatase.

Fecha de recepción: 12-05-2011

Aprobado para publicación: 21-11-2011

INTRODUCCIÓN

El consumo de frutas exóticas se ha incrementado en los últimos años mundialmente y Colombia se ha convertido en el primer exportador de uchuva (Physalis peruviana L.), en especial a Europa (CCI, 2006).

Para la optimización de su cultivo se ha requerido emplear sistemas químicos de fertilización, pero el interés de los consumidores por obtener productos de alta calidad, que llenen sus expectativas sin exceder costos y conservar integralmente los recursos incluyendo el suelo, ha favorecido el desarrollo de productos biológicos que mejoren la eficiencia de los fertilizantes químicos como mecanismo para favorecer la sostenibilidad de los agroecosistemas (CCI, 2001; 2006). A pesar que los fertilizantes químicos han sido muy utilizados para el mejoramiento de los cultivos, una gran porción del fosfato inorgánico soluble es in- movilizado químicamente convirtiéndose en no disponible para plantas, por lo que con frecuencia es necesario aplicar a los cultivos formas solubles de fósforo. Además se ha estimado que la proporción de fósforo utilizado de los fertilizantes por las plantas es solo de $5-25 \%$, por lo cual se requieren aplicaciones continúas de fertilizante incrementando los costos y efectos adversos sobre suelos y agua (Chen et al., 2006).

En los últimos años ha crecido el interés en usar microorganismos con la habilidad de solubilizar fosfatos minerales y orgánicos, a través de procesos que incluyen la acidificación, quelación y reacciones de óxido-reducción (Harris et al., 2005). Esto ha llevado al uso de microorganismos solubilizadores de fosfato como biofertilizantes eficientes para incrementar la nutrición de fósforo en diferentes cultivos. 
Teniendo en cuenta que Colombia es el mayor productor de uchuva del mundo, para este cultivo se quiere motivar el uso de microorganismos como biofertilizantes alternos a los de síntesis química utilizados actualmente.

El propósito de este trabajo fue aislar microorganismos de suelos de cultivos de uchuva, seleccionar y caracterizar cepas de microorganismos que presentaran la mayor actividad fosfato-solubilizadora para posteriormente ser utilizadas en proyectos futuros de biofertilizantes, con el fin de minimizar la aplicación de fertilizantes químicos a cultivos y contribuir reduciendo la contaminación ambiental.

\section{MATERIALES Y MÉTODOS}

La fase de campo se llevó a cabo en cultivos de uchuva para exportación, en el departamento de Cundinamarca: finca La Uvilla y finca Villa Silvania, localizadas en el municipio de Silvania y finca Las Margaritas en el municipio de Granada. Se aplicó un patrón no sistemático de muestreo irregular, en forma de X (Martínez et al., 2007) y se muestrearon cinco puntos en cada finca, de la rizósfera a una profundidad de $20 \mathrm{~cm}$, determinada por las raíces del cultivo (Martínez et al., 2007).

\section{Características del pH y análisis de fósforo total y disponible}

El pH se midió por triplicado, tomando $25 \mathrm{~g}$ de suelo y suspendiéndolo en $25 \mathrm{~mL}$ agua destilada $\mathrm{pH}$ 7,0. Se agitó durante $10 \mathrm{~min}$, se dejó en reposo por 30 min y se le midió el pH con pHmetro siguiendo el método de pasta de saturación (Warnke, 1990). El análisis de fósforo total se realizó por medio de técnica colorimétrica según el procedimiento del método oficial 4500-P D de la APHA, AWWA, WEF, y el análisis de fósforo disponible se realizó por el método de Bray II.

\section{Aislamiento de microorganismos solubilizado- res de fosfato}

Para aislar las cepas, se realizó una muestra compuesta de suelo por cada uno de los cinco puntos. Se efectuó un preenriquecimiento selectivo, para lo cual, a $10 \mathrm{~g}$ de suelo de cada muestra compuesta se adicionaron a $90 \mathrm{~mL}$ de medio SMRS (Sundara y Sinha, 1963) sin indicador y se llevó en agitación en shaker termostatado a $150 \mathrm{rpm}$ y $35^{\circ} \mathrm{C}$. Se realizaron diluciones seriadas en base 10 en tubos de agua peptonada al $0,1 \%(p / v)$, se hicieron diluciones desde $10^{-1}$ hasta $10^{-8}$ y se inoculó por duplicado en superficie en medio SMRS1 (Sundara y Sinha, 1963) por el método de microgota (Collins, 1989). Las cajas se incubaron a $35^{\circ} \mathrm{C}$ durante $2 \mathrm{~d}$ para recuperación de los microorganismos.

\section{Pruebas cualitativas de actividad solubilizadora de fosfato}

Inicialmente se realizaron aislamientos seguidos por siembra en agotamiento en medio SRMS1, a partir de las colonias que presentaron halos de solubilización en la técnica de microgota, hasta obtener colonias puras, las cuales se identificaron por características macroscópicas y microscópicas. Las cajas fueron incubadas a $35^{\circ} \mathrm{C}$ durante 2 a $3 \mathrm{~d}$.

\section{Pruebas cualitativas de solubilización}

Se inocularon tres viales de cada una de las cepas aisladas y conservadas, en $47 \mathrm{~mL}$ de medio SMRS1, en Erlenmeyer de $250 \mathrm{~mL}$ y se incubaron en shaker termostatado durante $36 \mathrm{~h}$ a $35^{\circ} \mathrm{C}$. Se colocó un anillo de plástico de diámetro de 5 mm en una caja de Petri con medio SMRS1 y se inocularon $50 \mu \mathrm{L}$ de cada Erlenmeyer los cuales presentaban una concentración de microorganismos en fase exponencial, cuya concentración se comprobó mediante recuento en microgota. Como control negativo se inoculó agua destilada 
estéril; posteriormente se realizó coloración de Gram, se incubaron durante 24 a $48 \mathrm{~h}$ a $35^{\circ} \mathrm{C}$ y a continuación se identificaron las colonias con halos de solubilización. Esta prueba se realizó por triplicado. El parámetro que se tuvo en cuenta para seleccionar las cepas con mayor capacidad solubilizadora, fue el índice de solubilización (IS) (suma diámetro de la colonia y el halo dividido por el diámetro de la colonia).

\section{Caracterización microscópica y bioquímica de las cepas solubilizadoras de fosfato}

Se realizó a partir de la coloración de Gram identificando morfología típica y para su caracterización bioquímica se emplearon kits Biomerieux ${ }^{\circledR}$ API 20E para las bacterias oxidasa negativa y API 20C AUX para la levadura.

\section{Curva de crecimiento}

La curva de crecimiento se realizó para cada una de las cepas seleccionadas con el fin de determinar la fase exponencial, usando un Erlenmeyer de $500 \mathrm{~mL}$ manteniendo la relación 1/5. Se evaluaron dos tratamientos, medio AG modificado y medio AG (Angulo et al., 2008) utilizando como controles el medio SMRS y SMRS1. Se cuantificó la biomasa por medio de la técnica de microgota, en agar SMRS1 y se evaluó la actividad fosfatasa, por el método de paranitrofenol fosfato, se evaluó igualmente biomasa producida en cada uno de los medios (medio AG modificado y medio AG, medio SMRS y SMRS1) y actividad

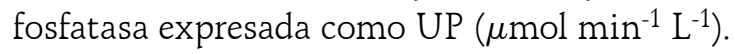

\section{Evaluación de la actividad fosfatasa}

Fase I: para la determinación de la actividad fosfatasa cuantitativa se tomaron $700 \mu \mathrm{L}$ de cada una de las muestras del cultivo en los diferentes medios evaluados, las cuales se hicieron reaccionar con $900 \mu \mathrm{L}$ de para-nitrofenil fosfato al $0,08 \%(\mathrm{v} / \mathrm{v})$ durante una hora a $35^{\circ} \mathrm{C}$, frenando la reacción con $1575 \mu \mathrm{L}$ de $\mathrm{NaOH} 20 \mathrm{mmol} \mathrm{L}^{-1}$ (Otálora et al., 2003). Las muestras se centrifu- garon a $5.000 \mathrm{rpm}$ durante 10 min y se evaluaron en espectrofotómetro a $450 \mathrm{~nm}$, utilizando un blanco con las mismas condiciones de los tratamientos y medios control, pero utilizando medio estéril. Los resultados se expresaron en $p$-nitrofenol ( $\left.\mu \mathrm{g} \mathrm{L}^{-1}\right)$, utilizando la ecuación hallada en la curva de calibración. La actividad enzimática fue expresada en términos de unidad fosfatasa, donde esta corresponde a la cantidad de enzima que se requiere para liberar $1 \mu \mathrm{mol}$ de p-nitrofenilfosfato por minuto y litro (Beltrán et al., 2005).

Fase II: se evaluaron nuevamente los medios AG, AG modificado, SMRS y SMRS1, y se evaluó un nuevo medio, BR (Bobadilla et al., 2008). Se utilizó cultivo completo y una concentración mayor a la anterior de p-nitrofenilfosfato al 0,1\% (p/v). La fermentación se llevó a cabo durante 20 h, con muestreos cada $4 \mathrm{~h}$ en shaker termostatado a $35^{\circ} \mathrm{C}$ y $150 \mathrm{rpm}$, determinando actividad fosfatasa (UP), biomasa (UFC $\mathrm{mL}^{-1}$ ) y $\mathrm{pH}$.

\section{Prueba de antagonismo}

Para esto se utilizó caldo SMRS1 crecido, de cada una de las cepas evaluadas, se incubaron durante el tiempo que cada una alcanzaba la fase exponencial verificando su concentración en medio SMRS1 por microgota. Se sembró por duplicado en forma masiva $0,1 \mathrm{~mL}$ del microorganismo y se colocaron tres anillos de plástico de $5 \mathrm{~mm}$ de diámetro, equidistantes sobre el agar, cada anillo se inoculó con $50 \mu \mathrm{L}$ de microorganismo antagonista y el otro con agua destilada estéril como control negativo (Duran y Bustillo, 1996).

\section{Curva de crecimiento del cultivo mixto}

Para ello se preparó un preinóculo de cada una de las cepas por separado, hasta alcanzar una concentración apróximada de ocho unidades logarítmicas, determinándolo por el método de microgota; en un Erlenmeyer de $100 \mathrm{~mL}$ con medio SMRS1 manteniendo las mismas condiciones de las curvas anteriores. Posteriormente, $10 \mathrm{~mL}$ de cada uno de los Erlenmeyer con cada cepa, se pasaron a un Erlenmeyer de $500 \mathrm{~mL}$ con cada uno 
de los medios a evaluar, se incubaron en shaker termostatado a $35^{\circ} \mathrm{C}$ y $150 \mathrm{rpm}$ por $22 \mathrm{~h}$. Se evaluaron los mismos parámetros de la fase I.

\section{Análisis estadístico de los datos}

Para la prueba de determinación de actividad fosfatasa, se aplicó el test de Chi-cuadrado para cada uno de los medios y cepas evaluadas. Para evaluar la producción de biomasa por medio de cultivo con las diferentes cepas, también se aplicó el test de Chi-cuadrado y el test de Wilcoxon / Kruskal-Wallis (Rank Sums).

\section{RESULTADOS Y DISCUSIÓN}

El $\mathrm{pH}$ de los suelos muestreados fue ácido, presentó valores de 4,08; 5,01 y 5,5 en las fincas La Villa, Villa Silvania y Las Margaritas, respectivamente; no obstante, los suelos más recomendados para el cultivo de la uchuva deben tener un pH entre 5,5 y 6,8 (Fischer y Almanza, 1993). Los aislamientos de los microorganismos solubilizadores de fósfato en las fincas muestreadas, oscilaron entre $29 \times 10^{3}$ y $36 \times 10^{4}$ UFC mL m $^{-1}$ (tabla 1). En cuanto a la finca Villa Silvania y Las Margaritas, la población de estos microorganismos fueron similares a las obtenidas por Caballero et al. (2006) en suelos ácidos de los Llanos Orientales. Estos mismos autores indican que la supervivencia de estos microorganismos a $\mathrm{pH}$ por debajo de 5,5 es más difícil, no solo por la condición libre de $\mathrm{H}^{+}$que desplazan otros iones, sino también porque solo pueden actuar las fosfatasas ácidas producidas por los microorganismos, lo cual limita su crecimiento. De estos aislamientos, se obtuvieron aislamientos que presentaron características morfológicas y coloración de Gram diferente, por lo cual se tomaron cinco cepas.

La determinación de la capacidad de solubilización y la selección semicuantitativa de los microorganismos con capacidad solubilizadora de fosfato, se realizó basándose por presencia de halos de solubilización y en el índice de solubilización hallado en medio sólido SMRS1. De este modo de las cinco cepas aisladas y purificadas, se seleccionaron tres cepas (3.F1p4; 5.F2p2 y 6.F3p2) que presentaron un índice de solubilización (IS) mayor a 2,3 (tabla 3) considerado aceptable para un microorganismo fosfato solubilizador según Otalora et al. (2003). Sin embargo los IS de las diferentes cepas aisladas no mostraron diferencias significativas entre sí.

Posteriormente las cepas seleccionadas fueron identificadas como Candida famata, Aeromonas hydrophila y Rahnella aquatilis.

Ninguna de las cepas aisladas ha sido anteriormente reportada como solubilizadoras de fosfato, pero se conocen por diferentes aplicaciones en el campo agronómico. Candida famata es una levadura esporógena y criotolerante (en su forma teleomorfa se conoce como Debaryomyces hansenii). Algunas cepas de D. hansenii están en estudio para su utilización para producir xilitol (Ishchuk et al., 2008). Normalmente crece en medios de fuentes de carbono simples como glucosa presentando colonias de color blanco a crema, de textura cremosa, microscópicamente se observa en forma ovoide como células de levadura o blastoconidias. Se conoce que C. famata (F35) ha sido aislada de hojas de una planta de breva del

Tabla 1. Recuento de microorganismos.

\begin{tabular}{|l|c|c|}
\hline \multicolumn{1}{|c|}{$\begin{array}{c}\text { Fincas muestreadas } \\
\text { de Cundinamarca }\end{array}$} & $\begin{array}{c}\text { Promedio de heterótrofos cultivables } \\
\text { (UFC mL } \mathrm{L}^{-1} \text { ) } \\
\text { La Uvilla (Silvania) }\end{array}$ & $\begin{array}{c}\text { Promedio de microorganismos fosfato } \\
\text { solubilizadores (UFC } \mathrm{L}^{-1} \text { ) }\end{array}$ \\
\hline Villa Silvania (Silvania) & $21 \times 10^{7}$ & $29 \times 10^{3}$ \\
\hline Las Margaritas (Granada) & $32 \times 10^{8}$ & $39 \times 10^{4}$ \\
\hline
\end{tabular}


Tabla 2. Aislamientos cepas con características solubilizadoras de fosfato.

\begin{tabular}{|l|l|l|l|}
\hline $\begin{array}{c}\text { Codificación } \\
\text { cepa }\end{array}$ & \multicolumn{1}{|c|}{ Muestra } & \multicolumn{1}{c|}{ Microscópica } & \multicolumn{1}{c|}{ Macroscópica } \\
\hline 2. F1p4 & Finca No. 1, La Uvilla, punto 4 & Levaduras & $\begin{array}{l}\text { Colonias grandes, cremosas, } \\
\text { blancas }\end{array}$ \\
\hline 3. F1p4 & Finca No. 1, La Uvilla, punto 4 & Levaduras & $\begin{array}{l}\text { Colonias grandes, cremosas, } \\
\text { amarillo oscuro }\end{array}$ \\
\hline 5. F2p2 & Finca No. 2, Villa Silvania, punto 2 & Bacilos cortos Gram negativos & $\begin{array}{l}\text { Colonias grandes, cremosas, } \\
\text { brillantes, color beige }\end{array}$ \\
\hline 6. F3p2 & Finca No. 3, Las Margaritas, punto 2 & Bacilos cortos Gram negativos & $\begin{array}{l}\text { Colonias pequeñas, cremosas, } \\
\text { blancas }\end{array}$ \\
\hline 7. F3p2 & Finca No. 3, Las Margaritas, punto 2 & Bacilos cortos Gram positivos & $\begin{array}{l}\text { Colonias pequeñas, cremosas } \\
\text { amarillo claro }\end{array}$ \\
\hline
\end{tabular}

Tabla 3. Índices solubilización de cada una de las cepas aisladas inicialmente. a. SMRS1 (trifosfato).

\begin{tabular}{|l|c|}
\hline Cepa & IS \\
\hline 2. F1p4 & 1,6 \\
\hline 3. F1p4 & 2,6 \\
\hline 5. F2p2 & 2,4 \\
\hline 6. F3p2 & 3,0 \\
\hline 7. F3p2 & 1,7 \\
\hline
\end{tabular}

noroccidente de Sardinia (Italia) y se ha reportado a nivel ambiental como un biocontrolador de Penicillum digitatum (Arras, 1996).

Aeromonas hidrophila, bacilo Gram negativa, heterótrofa, anaerobia facultativa, crece entre 10 y $42^{\circ} \mathrm{C}$, en pH de 4,5 a 9,0 (López et al., 2006). Se ha reportado que posee una proteoenzima muy eficaz en comparación con otras bacterias del mismo género y es considerado un descontaminante efectivo de suelos y aguas subterráneas contaminadas con organofosforados (Park et al., 2003). A. hydrophila posee la capacidad de sulfato-reducción desasimilatoria y mecanismos de resistencia como la thiopurina reductasa, arsenito reductasa y enzimas de degradación del fosfonato contra compuestos tóxicos encontrados en aguas contaminadas (Seshadri et al., 2006).

Rahnella aquatilis, bacilo Gram negativo, psicrotrófico, con propiedades fenotípicas y metabólicas, por las que ha sido estudiado como un posi- ble agente biocontrolador en diferentes plantas. Bacteria epifítica que ha sido aislada de frutas y hojas de árboles de manzanas, también estudiada por sus propiedades antagónicas contra Penicillium expansum y Botrytis cinerea en manzanas rojas, aunque no produce antibióticos extracelulares. El hábitat natural de $R$. aquatilis es el agua, aunque también aislado de hojas de plantas (Hashidoko et al., 2002), suelo y alimentos (Calvo y Sanz, 2007). Considerado como un microorganismo innovador, por ser útil como agente biocontrolador que produce sideróforos que, a su vez, pueden ser una herramienta importante para controlar los patógenos en poscosecha. También tiene habilidad de fijar nitrógeno atmosférico y de solubilizar fosfato mineral (Kim et al., 1997, 1998), capaz de producir agentes quelantes los cuales serían importantes en este tipo de suelo ácido donde los metales tienden a formar quelatos con los fosfatos.

En la producción de biomasa de C. famata se encontraron diferencias significativas en los diferentes medios de cultivo $(P<0,027)$. La biomasa en los medios SMRS y SMRS1 presentó una mayor producción por encima de la media general, comparado con los medios AG modificado y AG, como se esperaba, ya que los dos primeros son medios controles utilizados usualmente para el crecimiento de microorganismos fosfato solubilizadores. Esto pudo haber ocurrido debido a que la fuente de carbono de SMRS y SMRS1 es 
glucosa (monómero asimilable facilmente) a diferencia de los otros dos que presentan sacarosa (disacárido). Respecto a la fuente de fósforo inorganico no se encontraron diferencias estadisticamente significativas en el crecimiento de C. $f a$ mata, aunque SMRS y SMRS1 tengan diferente fuente de fósforo inorgánico, igualmente entre los medios AG modificado y AG.

Respecto a la curva de biomasa de A. hydrophila no se encontraron diferencias significativas entre la biomasa en los medios de cultivo evaluados $(P<0,167)$. Sin embargo, el medio SMRS1 presentó un mayor crecimiento junto con el medio SMRS, a diferencia de los medios AG modificado y AG tampoco se evidenciaron diferencias significativas en la biomasa de $R$. aquatilis en los diferentes medios de cultivo $(P<0,382)$. Sin embargo, los medios de cultivo SMRS y SMRS1 presentaron una mayor biomasa por encima de la media general a diferencia de los medios AG modificado y AG.

La biomasa del inóculo mixto no presentó diferencias significativas en los medios evaluados, sin embargo se observó que en el medio SMRS1 y BR que contienen glucosa y sacarosa, respectivamente, como fuente de carbono, roca fosfórica fuente de fósforo inorgánico, extracto de levadura fuente de fósforo orgánico y otras sales como microelementos, además de quinua (solo el medio $\mathrm{BR}$ ), se obtuvo una mayor producción de biomasa en comparación a los medios SMRS, AG modificado y AG. Siendo el medio BR el que presentó el mejor crecimiento, lo cual pudo haberse evidenciado a la quinua un sustrato que provee otra fuente de carbono adicional a la sacarosa y al mismo tiempo una gran fuente de nitrógeno, contiene 10 de los aminoácidos esenciales y un alto contenido de fósforo (408,3 mg por $100 \mathrm{~g}$ ), los cuales le permiten a los microorganismos tener una tasa de crecimiento más alta.

Los valores de la curva de $\mathrm{pH}$ individuales en cada uno de los medios, no presentaron diferencias estadísticamente significativas; sin embar- go, los medios SMRS1 y BR presentaron valores de $\mathrm{pH}$ menores a los otros medios. El medio BR, en la evaluación de las tres cepas aisladas, presentó el menor $\mathrm{pH}$ ya que por el gran contenido de nutrientes de la quinua, los microorganismos pudieron haber llevado a cabo la fermentación de estos, donde los principales productos son ácidos grasos de cadena corta, succínico, aminovalérico $\mathrm{y}_{2}$, los cuales llevan a una mayor acidificación del medio; por tanto, el descenso de $\mathrm{pH}$ puede estar relacionado con la fermentación de los aminoácidos presentes y por la composición del medio que indujo a un metabolismo más activo de estos microorganismos.

En el pH del cultivo mixto (figura 1), se evidenciaron diferencias significativas en el $\mathrm{pH}$ de los diferentes medios de cultivo analizados $(P<0,020)$. Las diferencias se presentaron entre los medios AG modificado y SMRS1; AG y SMRS1; y SMRS1 y SMRS. Los medios SMRS1 y BR presentaron un $\mathrm{pH}$ bajo respecto a la media general, mientras que los demás medios se encontraron por encima de $\mathrm{pH}$ 6,5. Este $\mathrm{pH}$ bajo obtenido puede estar ligado a la producción de ácidos, lo cual se relaciona con uno de los mecanismos de solubilización de fosfato de las cepas de bacterias solubilizadoras de fosfato que es la producción de ácidos orgánicos de bajo peso molecular (Kim et al., 1997; Delvasto et al., 2008). Las tres cepas produjeron $\mathrm{pH}$ bajo en los medios evaluados, producto de los ácidos orgánicos liberados, lo cual también se corroboró con los índices de solubilización hallados.

Los microorganismos fueron también evaluados para producción de fosfatasas con el fin de determinar si estos podían aportar en la solubilización de fósforo orgánico, contenido en la materia orgánica del suelo, y comparar su producción en diferentes medios, ya que los compuestos de fósforo orgánico constituyen de 4 a 90\% del fósforo total en el suelo, de ahí la importancia de la mineralización de fósforo orgánico en el suelo, porque su resultado es la liberación de fósforo inorgánico, el cual puede ser posteriormente dis- 


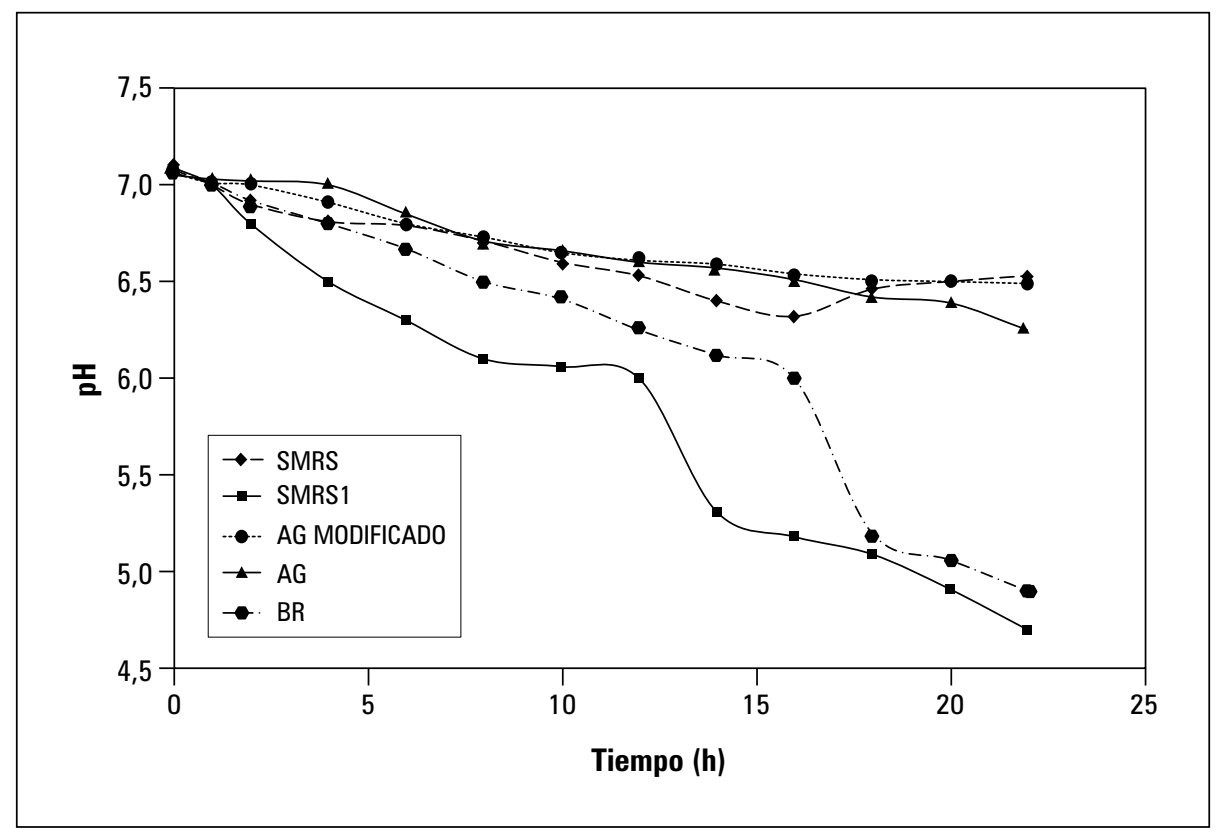

Figura 1. Comportamiento del pH del cultivo mixto en los medios de cultivo evaluados.

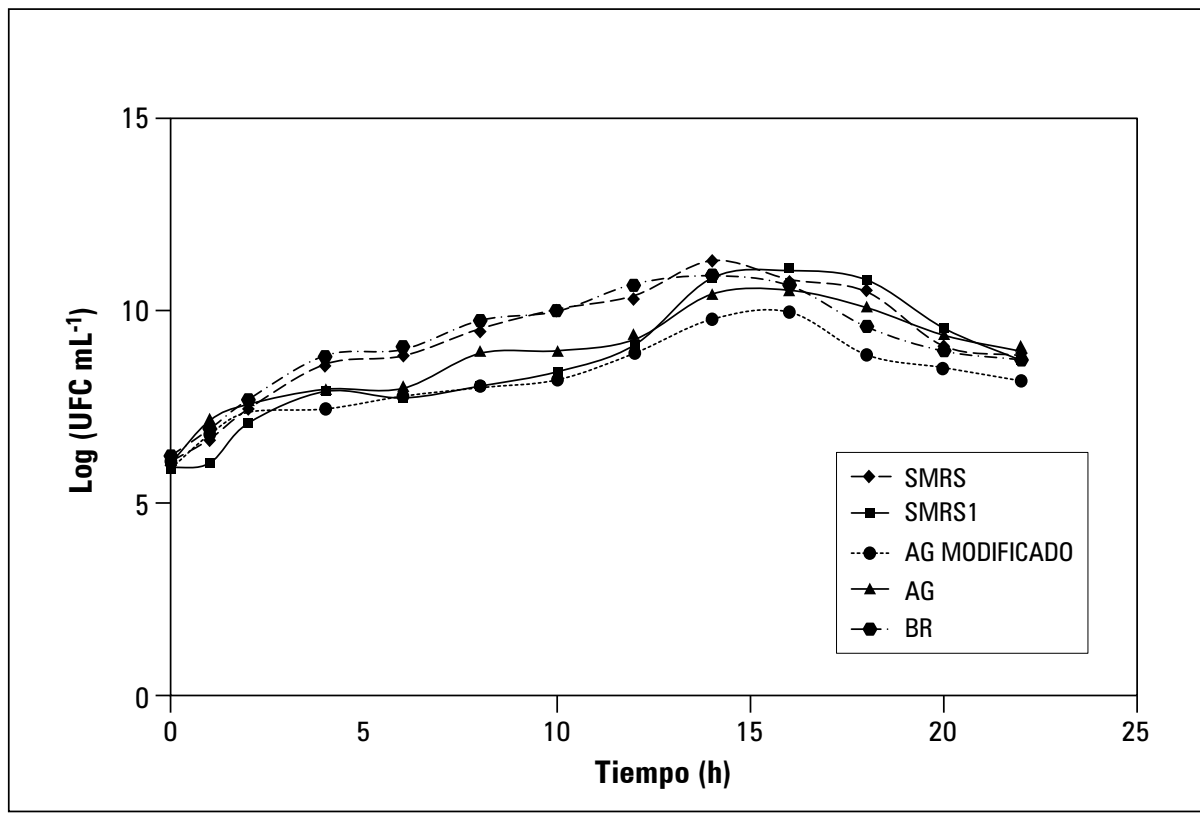

Figura 2. Curva de crecimiento del cultivo mixto en los medios de cultivo.

ponible para las plantas y microorganismos del suelo (Johri et al., 1999).

En la evaluación de la actividad fosfatasa fase I en la cual se utilizaron las condiciones estandarizadas por Otálora et al. (2003), durante 22 h se midió la actividad fosfatasa de cada una de las cepas en los medios evaluados, no se encontró una expresión significativa de la enzima en ninguno de los medios por parte de los microorganismos. Las curvas individuales se repitieron nuevamente para evaluar la expresión de las fosfatasas con las 
mismas condiciones de la técnica del p-nitrofenil fosfato anteriormente utilizadas, pero aumentando la concentración de p-nitrofenil a $0,1 \%$ (p/v) ya que según Barroso et al. (2006) con esta concentración se obtuvieron resultados óptimos. Además se trabajó con cultivo completo, donde han sido obtenidos mejores resultados en estudios anteriores a diferencia cuando se ha utilizado extracto crudo (Akcakaya et al., 2007). Se ajustó el pH del preinóculo ya que según Otalora et al. (2003) la técnica del p-nitrofenilfosfato se invalidaba a valores de $\mathrm{pH}$ menores a 5,0, por lo que se quiso descartar la posibilidad de que no se pudieran identificar estas enzimas debido a los bajos valores de $\mathrm{pH}$ obtenidos en las diferentes curvas realizadas.

Esta se denominó como la fase II. Aunque nuevamente no se detectaron fosfatasas en las curvas realizadas a cada cepa individual, en las curvas del cultivo mixto (figura 3) se evidenciaron estas enzimas en medio SMRS y BR. En líneas generales, las diferencias existentes con relación a la producción de fosfatasas ácidas y alcalinas (extracelulares e intracelulares), están asociadas no solo a los mecanismos de inducción y regulación enzimática (Joner y Johansen, 2000) o a las demandas nutricionales y a la disponibilidad de nutrientes (Dighton, 1991), sino también a las diferentes combinaciones e interacciones de las isoenzimas de las fosfatasas (Kroehler, 1988); es decir, que estas diferencias pueden estar controladas poligenéticamente (Gómez, 2004).

Teniendo en cuenta que la producción de fosfatasas se puede ver inducida por cantidades limitantes de fósforo inorgánico, otra razón del incremento de la expresión de la enzima en el cultivo mixto, pudo haber sido que la fuente de fosfato inorgánico (extracto de levadura), presente en los dos medios en los cuales se obtuvo la mayor cantidad de UP posiblemente se asimilaron a una velocidad mayor y así mismo convirtiéndose este en una limitante, activando la producción de la enzima más rápidamente. Este mecanismo es válido para A. hydrophila y R. aquatilis por ser bacterias y funcionar por medio de operones, pero no en Eucariotas como C. famata. No se encontró información disponible de esta levadura como fosfato solubilizadora de fósforo orgánico.

Sin embargo, se encontró que el mecanismo de transporte de fosfatos en las células eucariotas ocurre por un mecanismo diferente al de bacterias, en estudios anteriores han encontrado que algunas células eucariotas presentan unas proteínas denominadas DING. Las proteínas PstS son los elementos de unión a los fosfatos presentes en los mecanismos $\mathrm{ABC}$ para la asimilación de fosfatos en bacterias, y una de las clases de estas proteínas son las DING, las cuales han sido aisladas también de varias células eucariotas. La función de unión a fosfatos de estas proteínas sugiere un rol importante en la biomineralización, han sido detectadas tanto intracelularmente como extracelularmente, se conoce muy poco sobre estas proteínas, ya que ha sido muy escaso el estudio en cuanto a su estructura, función y genética (Berna et al., 2008).

En este estudio, los sustratos que sirvieron como inductores de la enzima de interés en todos los medios evaluados fueron el extracto de levadura, la levadura inactiva o quinua. El medio BR fue donde se observó una mayor producción de la enzima fosfatasa (figura 4). Este medio contiene alta cantidad de proteína y mayor proporción de fósforo orgánico gracias a la quinua, adicional al extracto de levadura, única fuente de fósforo orgánico presente en los otros medios.

Criquet et al. (2004) encontraron que la acción de las fosfatasas ácidas, como las encontradas en este estudio, se correlacionó con la temperatura, aunque más con humedad y concentración de proteínas presente en el medio. Por tanto, la cuantificación de la acción de las fosfatasas puede ser un proceso complejo, al depender de tantas variables para obtener los resultados más óptimos en su actividad, y el medio BR fue el que mejor las proporcionó para este tipo. 


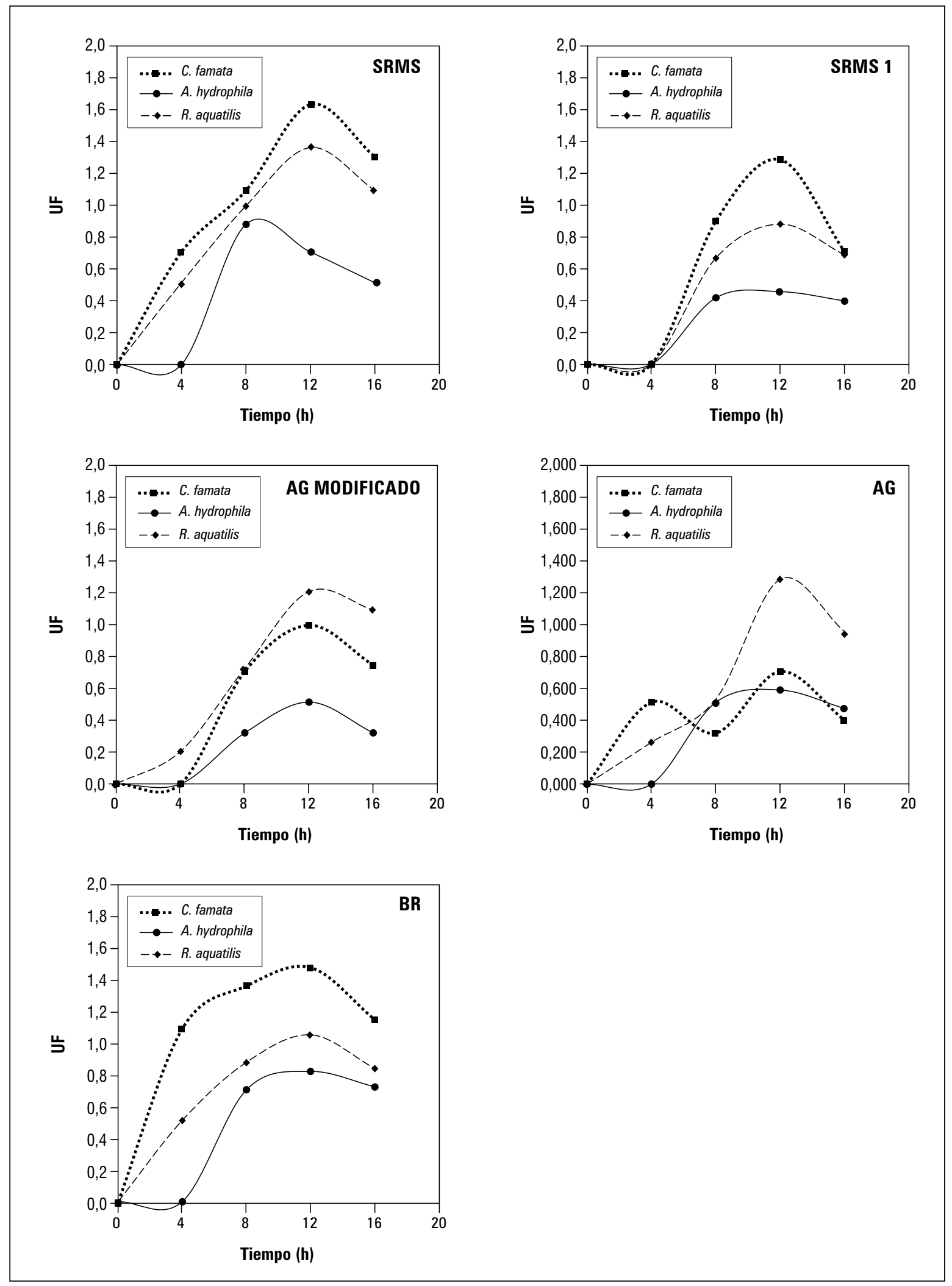

Figura 3. Determinación de actividad fosfatasa de las tres cepas aisladas en los medios evaluados. 


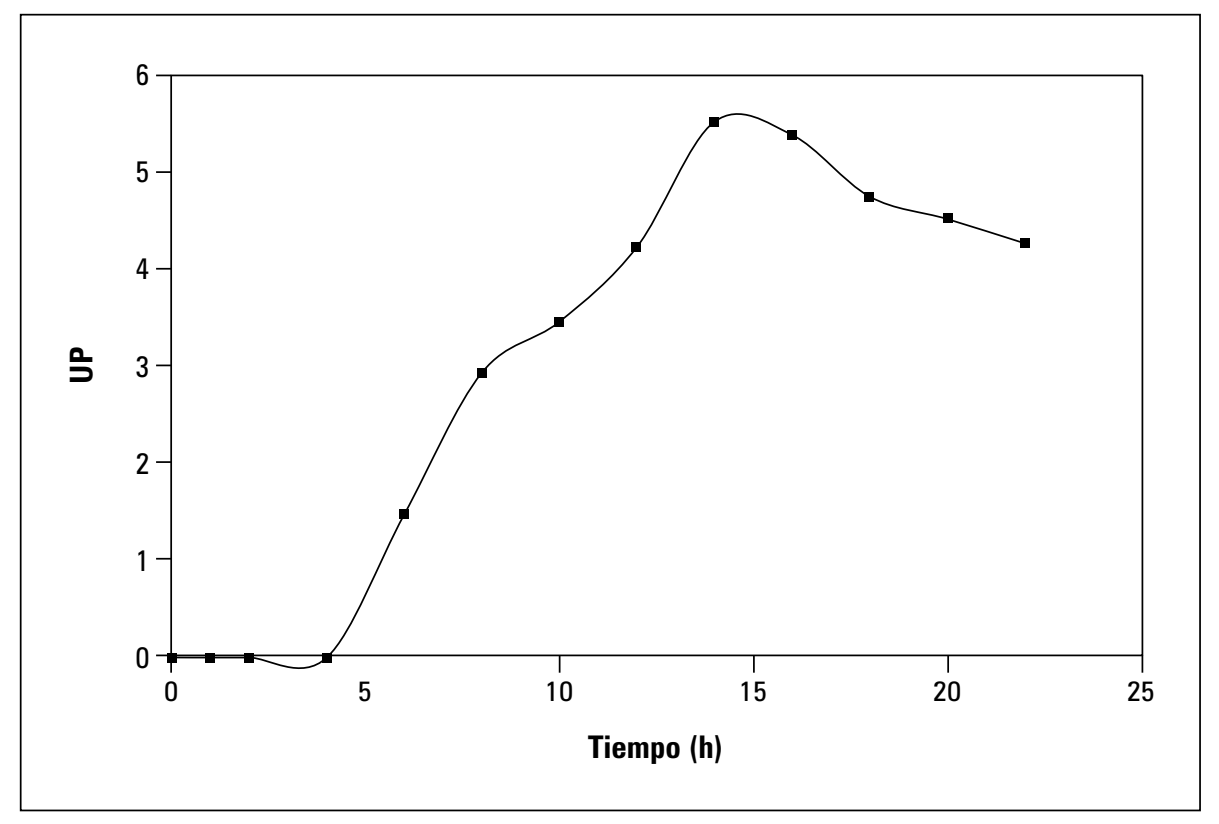

Figura 4. Mayor actividad fosfatasa obtenida.

Al comparar la actividad fosfatasa en las fases I y II se obtuvieron resultados más altos en las fases II, aunque no presentaron diferencias estadísticamente significativas. En el cultivo mixto sí se encontró una producción de la enzima, lo cual pudo haber sido resultado de los cambios realizados en la fase II, una mayor concentración de $\mathrm{p}$-nitrofenilfosfato $0,1 \%(\mathrm{p} / \mathrm{v})$, cultivo completo y ajuste inicial de $\mathrm{pH}$, ya que al utilizar una concentración del p-nitrofenilfosfato la enzima tenía una mayor cantidad de sustrato para actuar y al haber utilizado cultivo completo no solo se evaluaba la presencia de fosfatasas extracelulares sino también las intracelulares. Algunas de las fosfohidrolasas son secretadas al exterior de la célula a la membrana plasmática, donde estas son liberadas en una forma soluble o retenida como proteínas de unión de membrana (Rodriguez y Fraga, 1999), lo cual no se podía evaluar en la fase I, por ser extracto crudo.

Por razones económicas, la glucosa o sacarosa puras rara vez son utilizadas como única fuente de carbono, excepto en los procesos que exigen un control exacto de la fermentación y entre las dos se prefiere utilizar la sacarosa, por ser más economica. Al igual que la fuente de fósforo orgánico, siendo roca fosfórica más económica que trifosfato tricalcico; teniendo en cuenta estos tres aspectos, se seleccionó el medio BR.

La cantidad de fósforo disponible indica la fracción más inmediata utilizada por la planta para su respectivo desarrollo, por tanto, una variación en tal fracción sería la responsable en los cambios de crecimiento de la planta. Existe otro factor que puede incrementar la actividad de las fosfatasas, este es, según Portilla et al. (1998), la actividad de la fosfatasa ácida es más alta en la superficie de la raíz de la planta cuando existe deficiencia de fósforo, en el caso de los suelos estudiados, dos de ellos presentaron una deficiencia de fósforo disponible, lo cual podría coincidir con una alta actividad de las enzimas producidas por los microorganismos aislados de estos suelos.

Aunque el uso de microorganismos como biofertilizantes es una alternativa menos costosa y más favorable para el ambiente, la viabilidad y la actividad enzimática de los microorganismos se pue- 
den ver altamente afectadas bajo condiciones de estrés, como altas concentraciones de sales, $\mathrm{pH}$ y temperatura ambientales (Johri et al., 1999). Siendo el $\mathrm{pH}$ de los cultivos de uchuva generalmente ácido, como se encontró en las muestras, podría no ser favorable para el crecimiento y supervivencia de muchos microorganismos solubilizadores de fosfato conocidos, ya que muchos de los estudios disponibles con este tipo de microorganismos se han realizado en suelos alcalinos, existe poca información disponible acerca de microorganismos solubilizadores de fosfato en suelos ácidos.

La tolerancia al estrés producido por un $\mathrm{pH}$ bajo es un factor importante para la supervivencia y crecimiento de los microorganismos solubilizadores de fosfato que se desean aplicar al suelo ácido; puede darse el caso que se aplique un bioinoculante que ya se conoce, tiene buen efecto en la solubilización de fosfatos, pero es variable el efecto que se va a obtener en determinados suelos. Por esta razón es importante que los microorganismos solubilizadores de fosfato aislados en este estudio hayan sido aislados de un suelo con pH ácido, asegurando una mejor adaptación y viabilidad de estos microorganismos al momento de utilizarlos como biofertilizantes en suelos ácidos.

Según las pruebas realizadas, se obtuvo que las fosfatasas producidas por los tres microorganismos aislados, son fosfatasas ácidas, su mejor actividad es a valores bajos de $\mathrm{pH}$ como al que se verían expuestas en el suelo de este tipo de cultivos.

Para la determinación del fósforo en el suelo se utiliza usualmente el método Bray II. La extracción se efectúa en una mezcla de 0,003 N NH4F y 0,1 NHCL. Para poder realizar una buena extracción del fósforo total en forma de ortofosfatos, se realiza con una serie de oxidaciones que pueden ser por vía seca (calentando bastante tiempo en una mufla) o por ataque de determinados ácidos (Drummond y Maher, 1994). La técnica para la cuantificación de fósforo total fue una combinación de oxidaciones y calentamiento en muflas, se valoró con el método de vanadato-molibdato o una reacción conocida como de misson, específica entre las especies de fósforo como ortofosfato, y es posible que se presenten otras especies de fósforo por las condiciones en las que se llevó a cabo la extracción. Por otra parte, si las especies favorables no se obtienen, no se presenta la coloración característica de esta técnica, posiblemente los compuestos formados de fósforo no fueron estables y en estas condiciones aunque se pudiera encontrar el fósforo no se pudo detectar quizás porque no se formaron las especies que se esperaban de fósforo.

Por tanto, es recomendable realizar otro tipo de técnica, ya que por la colorimétrica, según el procedimiento del método oficial 4500-P, no se logró extraer fósforo total de las muestras de suelo; los resultados de cada suelo fueron de $3,2 \mathrm{mg}$ $\mathrm{L}^{-1}$, pues este es el límite mínimo de detección (tabla 4), por lo cual, no se puede realizar una comparación entre fósforo total y fósforo disponible de las muestras de suelo analizadas.

\section{CONCLUSIONES}

Como resultado de esta investigación se lograron aislar tres cepas nativas de suelos ácidos de cultivos de uchuva con capacidad solubilizadora de fosfato de suelos ácidos. Se aisló una levadura Candida famata y dos bacterias Aeromonas hydrophila y Rhanella aquatilis, las cuales al no haber presentado actividad antagónica entre sí, y ha-

\begin{tabular}{|c|c|c|}
\hline $\begin{array}{l}\text { Finca } \\
\text { muestreada }\end{array}$ & $\begin{array}{l}\text { Fósforo disponible } \\
\qquad\left(\mathrm{mg} \mathrm{L}^{-1}\right)\end{array}$ & $\begin{array}{l}\text { Fósforo total } \\
\qquad\left(\mathrm{mg} \mathrm{L}^{-1}\right)\end{array}$ \\
\hline La Uvilla & 16,6 & 3,2 \\
\hline Villa Silvania & 76,6 & 3,2 \\
\hline Las Margaritas & 16,1 & 3,2 \\
\hline
\end{tabular}


berse potencializándo su actividad solubilizadora de fósforo orgánico en inóculo mixto, además de haber presentado $\mathrm{pH}$ muy bajos en las fermentaciones por lo que podrían ser también solubilizadoras de fósforo inorgánico, pueden ser una muy buena opción para un futuro desarrollo de un bioinoculante mixto. Además se encontró que el medio innovador BR, puede ser una opción mejor costo-efectiva para el crecimiento de microorganismos, fosfato-solubilizadores.

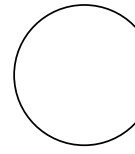

Akcakaya, H., A. Aroymak y S. Gokce. 2007. A quantitative colorimetric method of measuring alkaline phosphatase activity in eukaryotic cell membranes. Cell Biol. Int. 31,186-190.

Angulo, J., A. Garcia, M. Martinez y J. Casas. 2008. Evaluación de la aplicación en compost e inoculante a base de bacterias solubilizadoras de fosfato en un cultivo de palma de aceite (Elaeis guineensis) en etapa de vivero y renovación. Trabajo de grado. Pontificia Universidad Javeriana, Bogotá.

Arras, G. 1996. Mode of action of an isolate of Cundida famata in biological control of Penicillium digitatum in orange fruits. Postharvest Biol. Technol. 8,191-198.

Barroso, C., G. Pereira y E. Nahas. 2006. Solubilization of $\mathrm{CaHPO}_{4}$ and $\mathrm{AlPO}_{4}$ by Aspergillus niger in culture media with different carbon and nitrogen sources. Braz. J. Microbiol.37, 434-438.

Beltran, S., Y. Torrado, M. Martinez y A. Matiz. 2005. Aislamiento de bacterias con actividad fosfato solubilizadora y producción de un inoculo mixto en fermentación discontinua. Trabajo de grado. Programa de Microbiología Industrial, Pontificia Universidad Javeriana, Bogotá.

Berna, A., F. Bernier, E. Chabriere, T. Perera y K. Scott. 2008. DING proteins; novel members of a prokaryotic phosphate-binding protein superfamily which extends into the eukaryotic kingdom. Int. J. Biochem. Cell Biol.40, 170-175.

Bobadilla, C., C. Rincon y M. Martinez. 2008. Aislamiento y producción de bacterias fosfato solubilizadoras a partir de composta de residuos de plaza de la empresa bioagrícola del Llano, Villaviciencio. Trabajo de grado. Pontificia Universidad Javeriana, Bogotá.

Caballero, T., M. Camelo, R. Bonilla y M. Martínez. 2006. Aislamiento y caracterización de bacterias solubilizadoras de fosfato a partir de suelos algodoneros, departamentos de Cesar y meta. Trabajo de grado.

\section{REFERENCIAS BIBLIOGRÁFICAS}

Programa de Microbiología Industrial, Pontificia Universidad Javeriana, Bogotá.

Calvo, J. y M. Sanz. 2007. Biological control of postharvest spoilage caused by Penicillium expansum and Botrytis cinerea in apple by using the bacterium Rahnella aquatilis. Int. J. Food Microbiol.113, 251-257.

Chen, P., P.D. Rekha, A.B Arun, F.T. Shen, W.A. Lai y C. Young. 2006. Phosphate solubilizing bacteria from subtropical soil and their tricalcium phosphate solubilizing abilities. Appl. Soil Ecol. 34, 33-41.

Collins, C. 1989. Métodos microbiológicos. Editorial Acribia Zaragoza, España.

Corporación Colombia Internacional (CCI). 2001. Perfil producto No.13. Sistema de Inteligencia de Mercados. En: http://www.agronet.gov.co/www/ docs_agronet/2006327162612_uchuva_CCI actualizaci\%C3\%B3n.pdf; consulta: 9 de mayo de 2011

Corporación Colombia Internacional (CCI). 2006. Información de monitoreo internacional. Sistema de inteligencia de mercados. En: http://www.agronet. gov.co/www/docs_agronet/2006427154348 UCHUVAmarzo.pdf; consulta: 9 de mayo de 2011.

Criquet, S., E. Ferre, A. Farnet y J. Le Petit. 2004. Annual dynamics of phosphatase activities in an evergreen oak litter: influence of biotic and abiotic factors. Soil Biol. Biochem.36, 1111-1118.

Delvasto, P., A. Valverde, A. Ballester, J. Muñoz, F. Gonzalez, M. Blázquez, J. Igual y C. Garcia. 2008. Diversity and activity of phosphate bioleaching bacteria from a high-phosphorus iron ore. Hydrometallurgy 92, 124-129.

Dighton, J. 1991. Acquisition of nutrients from organic sources by mycorrhizal autotrophics plants. Experientia 47, 362-369.

Duran, L. y A. Bustillo. 1996. Aislamiento de bacterias fosfosolubilizadoras en fincas de los municipios de 
Bojacá, Gachancipá y Sopó en el departamento de Cundinamarca. Trabajo de grado. Carrera de Bacteriología, Pontifica Universidad Javeriana, Bogotá.

Drummond, L. y W. Maher. 1995. Determination of phosphorus in aqueous solution via formation of the phosphoantimonylmolybdenum blue complex Re-examination of optimum conditions for the analysis of phosphate. Analytica Chimica Acta 302(1) 69-74

Fischer, G. y P.J. Almanza. 1993. La uchuva (Physalis peruviana L.) una alternativa promisoria para las zonas altas de Colombia. Agricultura Tropical 30(1), 79-87.

Gomez, Y. 2004. Actividad de las fosfatasas ácidas y alcalinas (extracelulares e intracelulares) en hongos de la rizosfera de Arachis hypogaea (Papiloneaceae). Rev. Biol. Trop.52, 287-296.

Hashidoko, Y., E. Itoh, K. Yokota, T. Yoshida y S. Tahara. 2002. Characterization of five phyllosphere bacteria isolated from Rosa rugosa leaves, and their phenotypic and metabolic properties. Pub. Med. Biosci. Biotechnol. Biochem. 66(11), 2474-2478.

Harris, J., P. New y P. Martin. 2005. Laboratory tests can predict beneficial effects of phosphate-solubilising bacteria on plants. Soil Biol. Biochem. 38, 1521-1526.

Ishchuk, O., K. Dmytruk, O. Rohulya, A. Voronovsky, C. Abbas y A. Sibirny. 2008. Development of a promoter assay system for the flavinogenic yeast Candida famata based on the Kluyveromyces lactis-galactosidase LAC4 reporter gene. Enzyme Microb. Technol. 42, 208-215.

Johri, K., S. Surange y C. Nautiyal. 1999. Occurrence of salt, $\mathrm{pH}$, and temperature-tolerant, phosphate-solubilizing bacteria in alkaline soils. Curr. Microbiol. 39, 89-93.

Joner, E.J. y A. Johansen. 2000. Phosphatase activity of external hyphae of two arbuscular mycorrhizal fungi. Mycol. Res. 104, 81-86.

Kim, Y., D. Jordan y H. Krishnan. 1997. Rahnella aquatilis, a bacterium isolated from soybean rhizosphere, can solubilize hydroxyapatite. Microbiol. Lett. 153, 273-277.

Kim, Y., D. Jordan y H. Krishnan. 1998. Expression of genes from Rahnella aquatilis that are necessary for mineral phosphate solubilization in Escherichia coli. Microbiol. Lett. 159(1), 121-127.
Kroehler, C. 1988. The effects of organic and inorganic phosphorus concentration on the acid phosphatase activity of ectomycorrhizal fungi. Can. J. Bot.66, 750-756.

Lopez, M.Y., V. Perez, M. Martinez y B. Quevedo. 2006. Evaluación de un medio de cultivo no comercial para la producción de un bioinoculante empleado en un cultivo de flores. Trabajo de grado. Facultad de Microbiología, Pontificia Universidad Javeriana, Bogotá.

Martínez, M., G. Campos, C. Campos, A. Matiz, M. Rodríguez, L. Caceres, M. Flórez y J. Conde. 2007. Técnicas en microbiología de suelos y lodos. Editorial Javegraf, Bogotá.

Otalora, J., M. Patiño, M. Martínez y A. Pedroza. 2003. Estandarización de prueba para la detección de fosfatasa producida por bacterias solubilizadoras de fosfatos. Trabajo de grado. Programa de Microbiología Industrial, Pontificia Universidad Javeriana, Bogotá.

Park, I.J., J.C. Yoon, S.J. Park, E.H. Kim, Y.J. Cho y K.S. Shin. 2003. Characterization of the proteolytic activity of bacteria isolated from a rotating biological contactor. J. Microbiol. 41, 73-77.

Portilla, I., E. Molina, G. Cruz-Flores, I. Ortiz y G.G.B. Manske. 1998. Mycorrhizal arbuscular colonization, phosphatase activity and root length as response to the phosphorus stress in wheat and triticale cultivated in an andisol. Terra 16(1), 55-61.

Rodriguez, H. y R. Fraga. 1999. Phosphate solubilizing bacteria and their role in plant growth promotion. Biotechnol. Adv.17, 319-339.

Seshadri, R., S. Joseph, A. Chopra, J. Sha, J. Shaw, J. Graf, D. Haft, M. Wu, R. Ren, M. Rosovitz, R. Madupu, L. Tallon, M. Kim, S. Jin, H. Vuong, O. Stine, A. Ali, A. Horneman y J. Heidelberg. 2006. Genome sequence of Aeromonas hydrophila ATCC 7966T: jack of all trades. J. Bacteriol. 188(23), 8272-8282.

Sundara, R. y W. Sinha. 1963. Phosphate dissolving microorganims in the soil and rhizosfere. Indian J. Agric. Sci. 33,272-278.

Vassilev, N., M. Vassileva, M. Fenice y F. Federic. 2001. Inmobilized cell techology applied in solubilization of insoluble inorganic (rock) phosphates and P plant acquisition. Bioresource Technol.79, 263-271.

Warnke, D. 1990. Testing artificial growth media and interpreting the results. pp. 337-357. En: Westerman, R.L. (ed.). Soil testing and plant analysis. SSSA Book Series, Madison, WI. 